\title{
Clinical Stringency Greatly Improves Mutation Detection in Rett Syndrome
}

\author{
Julie Gauthier, Giovana de Amorim, Gevork N. Mnatzakanian, Carol Saunders, \\ John B. Vincent, Sylvie Toupin, David Kauffman, Judith St-Onge, \\ Sandra Laurent, Patrick M. Macleod, Berge A. Minassian, Guy A. Rouleau
}

\begin{abstract}
Background: Rett syndrome (RTT) is a severe neurodevelopmental disorder of girls, caused by mutations in the X-linked MECP2 gene. Worldwide recognition of the RTT clinical phenotype in the early 1980's allowed many cases to be diagnosed, and established RTT as one of the most common mental retardation syndromes in females. The years since then led to a refinement of the phenotype and the recent elaboration of Revised Diagnostic Criteria (RDC). Here, we study the impact of the presence versus the absence of the use of diagnostic criteria from the RDC to make a diagnosis of RTT on MECP2 mutation detection in Canadian patients diagnosed and suspected of having RTT. Methods: Using dHPLC followed by sequencing in all exons of the MECP2 gene, we compared mutation detection in a historic cohort of 35 patients diagnosed with RTT without the use of specific diagnostic criteria to a separate more recent group of 101 patients included on the basis of strict fulfillment of the RDC. Results: The MECP2 mutation detection rate was much higher in subjects diagnosed using a strict adherence to the RDC (20\% vs. $72 \%)$. Conclusions: These results suggest that clinical diagnostic procedures significantly influence the rate of mutation detection in RTT, and more generally emphasize the importance of diagnostic tools in the assessment of neurobehavioral syndromes.
\end{abstract}

RÉSUMÉ: Un examen clinique rigoureux améliore beaucoup la détection de mutations dans le syndrome de Rett. Introduction: Le syndrome de Rett (RTT) est une maladie neurodéveloppementale sévère observée chez les filles et causée par des mutations du gène MECP2 situé sur le chromosome X. L'identification à l'échelle mondiale du phénotype clinique du RTT au début des années 1980 a permis de diagnostiquer de nombreux cas et a démontré que le RTT est un des syndromes de retard mental les plus fréquents chez les filles. Depuis, la description du phénotype a été raffinée et des critères diagnostiques révisés (CDR) ont récemment été formulés. Nous avons étudié l'impact sur la détection de mutations du gène MECP2 de l'utilisation ou de la non-utilisation de ces critères diagnostiques pour poser le diagnostic de RTT chez des patientes diagnostiquées ou soupçonnées d'être porteuses du RTT. Méthodes: Au moyen de la chromatographie liquide à haute pression en condition dénaturante suivie du séquençage de tous les exons du gène MECP2, nous avons comparé la détection de mutations dans une cohorte historique de 35 patientes porteuses d'un diagnostic de RTT, fait sans l'aide de critères diagnostiques spécifiques, à un groupe de 101 patientes dont le diagnostic avait été posé sur la base des CDR. Résultats: Le taux de détection de mutations du gène MECP2 était beaucoup plus élevé chez les sujets dont le diagnostic était basé sur une utilisation rigoureuse des CDR (20\% vs 72\%). Conclusions: Ces résultats suggèrent que la démarche utilisée pour poser le diagnostic clinique influence le taux de détection de mutations dans le RTT et, de façon plus générale, souligne l'importance des outils diagnostiques dans l'évaluation des syndromes neurocomportementaux.

Can. J. Neurol. Sci. 2005; 32: 321-326

Rett Syndrome (RTT, OMIM 312750) is characterized by onset in the first 18 months of life of slowing and arrest of neurodevelopment paralleled with a loss of communication and motor skills acquired to that point. Purposeful hand movements are replaced by a semi-continuous hand-washing stereotype. Social interaction with the family disintegrates, resembling autistic withdrawal and, with the passage of time, a picture of profound mental retardation emerges. ${ }^{1}$ However, depending on mutation location and extent of $\mathrm{X}$-inactivation skewing, individuals with RTT may also exhibit milder phenotypes with preserved speech and ambulation, mild learning disability, or a clinical picture more similar to autism than to classical RTT. ${ }^{2-4}$ Because of X-linkage, mutations causing classical RTT in girls are generally embryonic-lethal in boys, although some rare mild mutations allow survival and a variety of neurodevelopmental phenotypes in males. ${ }^{5-7}$

Following mapping of the RTT candidate locus to Xq27-28, the first RTT-causing mutations in the four-exon MECP2 gene. ${ }^{8}$ Since then, analysis of exons 2 to 4 of the gene in 32 reports $^{9-13}$ revealed 221 different mutations in the large exons 3 and 4, nine

\footnotetext{
From the Department of Biology, McGill University, Montreal (JG);Centre Hospitalier de l'Université de Montréal Research Centre (JG, JS, SL, GAR, ST, DK), Montreal, Quebec, Canada; Division of Medical Genetics, Victoria General Hospital (PMM), Victoria, British Columbia, Canada; Department of Biology (GD), University of Victoria, Vancouver, British Columbia, Canada; Program in Genetics and Genomic Biology (GNM, BAM), Hospital for Sick Children, Toronto, Ontario, Canada; Clinical Molecular Genetics and Molecular Diagnostics Laboratory (CS), Children's Mercy Hospitals and Clinics, Kansas City, Missouri, USA; Neurogenetics Section (JBV), Centre for Addiction and Mental Health, Toronto, Ontario, Canada.; Faculté de Médecine (GAR), Université de Montréal, Montréal, Québec, Canada. Received December 2, 2004. AcCePted in FinAl FORM April 30, 2005 Reprint requests to: Guy A. Rouleau, Research Centre-CHUM, 1560 Sherbrooke Street East, Room Y-3633, Montreal, Quebec, H2L 4M1, Canada.
} 
account for $65 \%$ of all mutations in classical RTT patients. No mutations were found in exon 2, and until recently, exon 1 was not included in mutation analyses, because it was considered to be non-coding and representing merely an extension of the 5, untranslated region (UTR) (Figure). A recent re-evaluation of MECP2 splice variants showed that the major brain transcript of the gene utilizes only exons 1,3 and 4 , in which case the first exon becomes coding. ${ }^{14,15}$ As a result, three additional mutations, affecting exon 1, were recognized. ${ }^{14}$ We now call the new
MECP2 isoform MECP2E1 (E1 for translation initiation site in exon 1; nomenclature agreed upon at the international Rett Syndrome Research Foundation meeting, June 2004), and the originally identified isoform MECP2E2. The mutations described below are numbered according to the MECP2E1 open reading frame (Figure). Equivalent annotation from MECP2E2 is included in Table 1.

Initially described in $1966,{ }^{16}$ RTT was rediscovered in the early 1980's and prominently brought to international paediatric

Table 1: MECP2 mutation screening from our two cohorts of subjects

\begin{tabular}{|c|c|c|c|c|c|c|}
\hline \multicolumn{2}{|c|}{$M E C P E 1^{a}$} & \multicolumn{2}{|c|}{$M E C P E 2^{a}$} & \multirow[b]{2}{*}{ Exon } & \multirow[b]{2}{*}{ Recurrence } & \multirow[b]{2}{*}{ Reported } \\
\hline Nt Position & Amino Acid & Nt Position & Amino Acid & & & \\
\hline \multicolumn{7}{|l|}{ Group 1} \\
\hline $155 \mathrm{del} \mathrm{A}$ & Fs at 52, stop at 408 & 119 del A & Fs at 40 , stop at 372 & 3 & 1 & Yes \\
\hline 1218 del 2 & Fs at 430, stop at 439 & 1182DEL2 & Fs at 394 , stop at 403 & 4 & 1 & Yes \\
\hline $509 \mathrm{C}->\mathrm{T}$ & $\mathrm{T} 170 \mathrm{M}$ & $473 \mathrm{C}->\mathrm{T}$ & $\mathrm{T} 158 \mathrm{M}$ & 4 & 1 & Yes \\
\hline $538 \mathrm{C}->\mathrm{T}$ & $\mathrm{R} 180 \mathrm{X}$ & $502 \mathrm{C}->\mathrm{T}$ & $\mathrm{R} 168 \mathrm{X}$ & 4 & 1 & Yes \\
\hline $799 \mathrm{C}->\mathrm{T}$ & $\mathrm{R} 267 \mathrm{X}$ & $763 \mathrm{C}->\mathrm{T}$ & $\mathrm{R} 255 \mathrm{X}$ & 4 & 2 & Yes \\
\hline $916 \mathrm{C}->\mathrm{T}$ & R306X & $880 \mathrm{C}->\mathrm{T}$ & R294X & 4 & 1 & Yes \\
\hline $952 \mathrm{C}->\mathrm{T}$ & $\mathrm{R} 318 \mathrm{C}$ & $916 \mathrm{C}->\mathrm{T}$ & R306C & 4 & 1 & Yes \\
\hline \multicolumn{7}{|l|}{ Group2 } \\
\hline $1 \mathrm{~A}->\mathrm{T}$ & M1L & $1 \mathrm{~A}->\mathrm{T}$ & M1L & 1 & 1 & No \\
\hline GT del & Splice variant & GTdel & Splice variant & 1 & 1 & Yes \\
\hline $338 \mathrm{C}->\mathrm{G}$ & P113R & $302 \mathrm{C}-\mathrm{G}$ & P101R & 3 & 1 & Yes \\
\hline $352 \mathrm{C}->\mathrm{T}$ & R118W & $316 \mathrm{C}->\mathrm{T}$ & R106W & 3 & 1 & Yes \\
\hline $416 \mathrm{C}->\mathrm{T}$ & P139L & $380 \mathrm{C}->\mathrm{U}$ & P127L & 4 & 1 & No \\
\hline $433 \mathrm{C}->\mathrm{T}$ & $\mathrm{R} 145 \mathrm{C}$ & 397C->T & $\mathrm{R} 133 \mathrm{C}$ & 4 & 2 & Yes \\
\hline $434 \mathrm{C}->\mathrm{A}$ & $\mathrm{R} 145 \mathrm{H}$ & $398 \mathrm{C}->\mathrm{A}$ & $\mathrm{R} 133 \mathrm{H}$ & 4 & 1 & Yes \\
\hline $437 \mathrm{C}->\mathrm{G}$ & $\mathrm{S} 146 \mathrm{C}$ & $401 \mathrm{C}->\mathrm{G}$ & $\mathrm{S} 134 \mathrm{C}$ & 4 & 1 & Yes \\
\hline 458 ins $\mathrm{A}$ & Y153X & 422insA & Y141X & 4 & 1 & Yes \\
\hline $491 \mathrm{C}->\mathrm{G}$ & P164R & $455 \mathrm{C}->\mathrm{G}$ & P152R & 4 & 1 & Yes \\
\hline $505 \mathrm{~T}->\mathrm{C}$ & F169L & $469 \mathrm{~T}->\mathrm{C}$ & F157L & 4 & 1 & Yes \\
\hline $508 \mathrm{~A}->\mathrm{G}$ & $\mathrm{T} 170 \mathrm{~A}$ & $472 \mathrm{~A}->\mathrm{G}$ & $\mathrm{T} 158 \mathrm{~A}$ & 4 & 1 & Yes \\
\hline $509 \mathrm{C}->\mathrm{T}$ & $\mathrm{T} 170 \mathrm{M}$ & $473 \mathrm{C}->\mathrm{T}$ & $\mathrm{T} 158 \mathrm{M}$ & 4 & 16 & Yes \\
\hline $538 \mathrm{C}->\mathrm{T}$ & $\mathrm{R} 180 \mathrm{X}$ & $502 \mathrm{C}->\mathrm{T}$ & $\mathrm{R} 168 \mathrm{X}$ & 4 & 6 & Yes \\
\hline 622 del 4 & Fs at 232, stop at 220 & 586del4 & Fs at 196, stop at 208 & 4 & 1 & Yes \\
\hline 732 del C & Fs at 268 , atop at 259 & 696delC & Fs at 232, stop at 247 & 4 & 1 & Yes \\
\hline 786 del C & Fs at 286, stop at 300 & 750delC & Fs 250, stop at 288 & 4 & 1 & No \\
\hline $799 \mathrm{C}->\mathrm{T}$ & $\mathrm{R} 267 \mathrm{X}$ & $763 \mathrm{C}->\mathrm{T}$ & $\mathrm{R} 255 \mathrm{X}$ & 4 & 5 & Yes \\
\hline 842 del G & 305300 & 806delG & Fs at 269, stop at 288 & 4 & 1 & Yes \\
\hline $844 \mathrm{C}->\mathrm{T}$ & $\mathrm{R} 282 \mathrm{X}$ & $808 \mathrm{C}->\mathrm{T}$ & $\mathrm{R} 270 \mathrm{X}$ & 4 & 9 & Yes \\
\hline $850 \mathrm{C}->\mathrm{T}$ & $\mathrm{P} 284 \mathrm{~S}$ & $814 \mathrm{C}->\mathrm{T}$ & $\mathrm{P} 272 \mathrm{~S}$ & 4 & 1 & No \\
\hline $916 \mathrm{C}->\mathrm{T}$ & R306X & $880 \mathrm{C}->\mathrm{T}$ & R294X & 4 & 5 & Yes \\
\hline $941 \mathrm{C}->\mathrm{A}$ & P314H & $905 \mathrm{C}->\mathrm{A}$ & P302H & 4 & 1 & Yes \\
\hline $941 \mathrm{C}->\mathrm{T}$ & P314R & $905 \mathrm{C}->\mathrm{T}$ & P302R & 4 & 1 & Yes \\
\hline $952 \mathrm{C}->\mathrm{T}$ & R318C & $916 \mathrm{C}->\mathrm{T}$ & R306C & 4 & 6 & Yes \\
\hline $953 \mathrm{G}->\mathrm{A}$ & $\mathrm{R} 318 \mathrm{H}$ & $917 \mathrm{G}->\mathrm{A}$ & $\mathrm{R} 306 \mathrm{H}$ & 4 & 1 & Yes \\
\hline $1000 \mathrm{C}->\mathrm{A}$ & P334T & $964 \mathrm{C}->\mathrm{A}$ & P322T & 4 & 1 & Yes \\
\hline $1000 \mathrm{C}->\mathrm{G}$ & P334A & $964 \mathrm{C}->\mathrm{G}$ & P322A & 4 & 1 & Yes \\
\hline 1193 del 44 & Fs at 422, stop at 401 & $1157 \mathrm{del} 44$ & Fs 386, stop at 389 & 4 & 1 & Yes \\
\hline 1196 del 33 & Fs at 423 , stop at 488 & 1160del33 & Fs 387 , stop at 476 & 4 & 1 & Yes \\
\hline $1291 \mathrm{C}->\mathrm{T}^{\mathrm{b}}$ & $\mathrm{P} 431 \mathrm{~S}$ & $1255 \mathrm{C}->\mathrm{Tb}$ & $\mathrm{P} 419 \mathrm{~S}$ & 4 & 1 & No \\
\hline
\end{tabular}

${ }^{\text {a}}$ Base pair position and amino acids numbered according to the MECP2E1 and the MECPE2 transcript initiator codon (NCBI \# AY541280). ${ }^{b}$ MECP2 variant present in the mother. Fs: Frameshitf, del: deletion, nt: nucleotide position on the transcript. 


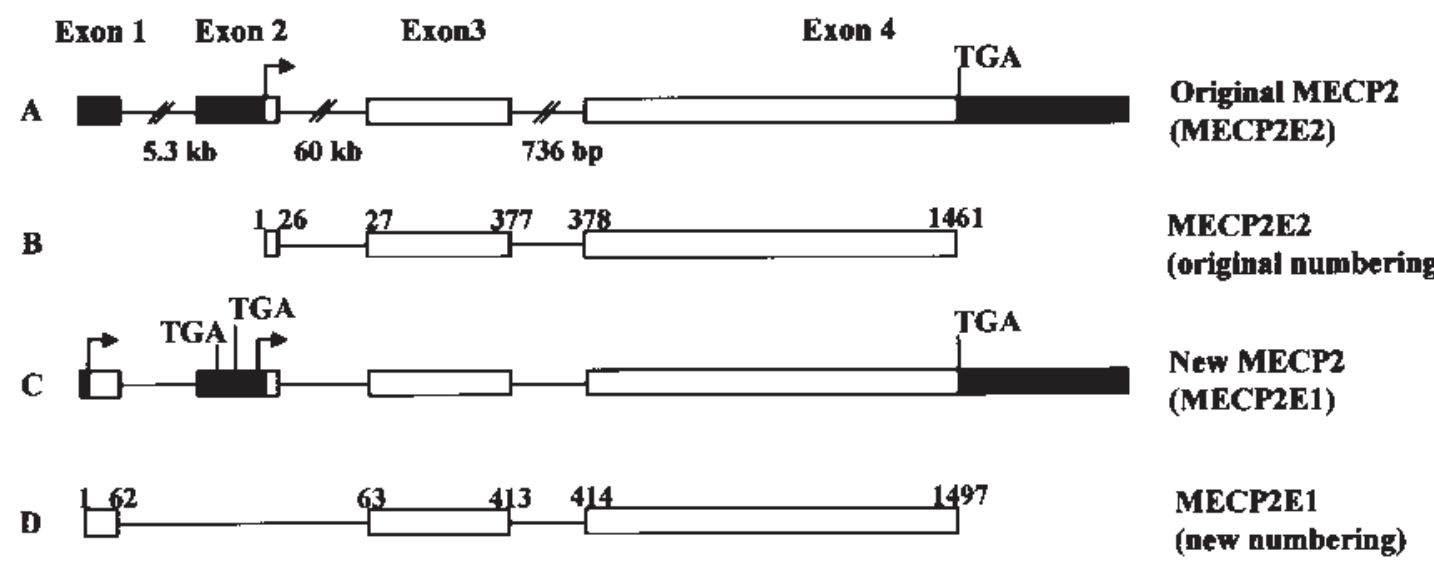

Figure: Schematic representation of the two MECP2 transcripts. (A) Original genomic organization of the MECP2 gene (MECPE2). (B) Original nucleotide numbering. (C) Genomic structure of the new MECP2 transcript (MECP2E1). (D) Novel nucleotide numbering according the MECPE1.Black boxes; untranslated regions; arrow; start site, TGA; stop codon, numbers represent nucleotides position.

attention. ${ }^{17}$ This allowed many cases to be diagnosed, and established RTT as one of the most common mental retardation conditions in females. ${ }^{18}$ It also led to a refinement of the RTT clinical phenotype in the early 1990s. The discovery of MECP2 mutations in RTT subjects added further knowledge in this disorder and, in 2001, an international effort was made to establish specific clinical guidelines to facilitate clinical diagnosis and recognition of the disorder. ${ }^{19}$ An updated list of criteria emerged and was called the «Revised Diagnostic Criteria (RDC)»(Table 2; http://www.rettsyndrome.org/main/diagnostic_ criteria.htm). ${ }^{19}$ Here, we study the impact of the presence versus the absence of the use of diagnostic criteria from the RDC to make a diagnosis of RTT on MECP2 mutation detection in Canadian patients diagnosed and suspected of having RTT.

\section{Patients And Methods}

All but one patient had been referred from various Canadian centres. This patient was referred from the Children's Mercy Hospitals and Clinics, Kansas City, Missouri, USA. In order to evaluate the impact of the use of specific criteria for RTT diagnosis on MECP2 mutation detection rate we subdivided the patients into two groups: we had one historic group (Group 1, Table 2) of patients without any final diagnosis merely a suspicion of RTT in whom specific diagnostic criteria for RTT were not used, and a more recent collection (Group 2) where patients were only accepted if they strictly met diagnostic criteria for RTT (Table 2). The referring physicians in both cases were not distinguishable in background. They were Canadian paediatricians, geneticists and paediatric neurologists.

The entire coding regions of exons 1, 2, 3 and 4 and their intronic flanking sequences were analyzed. Exons 2 to 4 were amplified by polymerase chain reaction (PCR) with primer pairs designed with the use of genomic sequence information from the Human Genome Project working draft site University of California Santa Cruz (UCSC, www.genome.ucsc.edu) and the

\section{Table 2: Revised Diagnostic Criteria (RDC) for RTT}

CRITERIA
Necessary
1. Apparently normal prenatal and perinatal history
2. Psychomotor development largely normal through the first
6 months or may be delayed from birth
3. Normal head circumference at birth
4. Postnatal deceleration of head growth in the majority
5. Loss of achieved purposeful hand skill between ages
1/2-2 $1 / 2$ years
6. Stereotypic hand movements such as hand
wringing/squeezing, clapping/tapping, mouthing and
washing/rubbing automatisms
7. Emerging social withdrawal, communication dysfunction,
loss of learned words, and cognitive impairment
8. Impaired (dyspraxic) or failing locomotion

Supportive 1. Awake disturbances of breathing (hyperventilation, breathholding, forced expulsion of air or saliva, air swallowing

2. Bruxism

3. Impaired sleep pattern from early infancy

4. Abnormal muscle tone successively associated with muscle wasting and dystonia

5. Peripheral vasomotor disturbances

6. Growth retardation

7. Hypotrophic small and cold feet; small, thin hands

Exclusion 1. Organomegaly or other signs of storage disease

2. Retinopathy, optic atrophy, or cataract

3. Evidence of perinatal or postnatal brain damage

4. Existence of identifiable metabolic or other progressive neurological disorder 5. Acquired neurological disorder resulting from severe infections or head trauma 


\section{Table 3: Cinical features present in subjects from Group 1}

\section{Case Mutation Clinical Features from Medical File}

1 NO GDD, seizures, regression, hypotonia, hand-wringing, short stature, obesity

10 NO GDD, seizures, microcephaly, spactic diplegia, dysmorphic features

11 119DELA GDD, hypotonia, hand-wringing, non-verbal, failing locomotion

$14 \quad \mathrm{NO}$

19 NO

27 R168X

$29 \quad \mathrm{NO}$

$29 \quad \mathrm{NO}$

34

35

38

39

40

41

42

45

46

48

5

51

64

65

65

77

77

78

8

81

82

84

86

89

90

92

95

Regression, seizures, hand-wringing, bruxism, abnormal breathing

GDD, not ambulatory, cerebellar hypoplasia

GDD, MR, seizures, not ambulatory

Not available

GDD, seizures, hypotonia, inappropriate laughter

Seizures, difficulty walking, brachycephaly, brain anomalies

$\mathrm{NO}$

$\mathrm{R} 255 \mathrm{X}$

NO

NO

NO

1182del2

NO

NO

$\mathrm{NO}$

NO

$\mathrm{NO}$

NO

NO

R306C

NO

NO

NO

NO

NO

NO

NO

R255X

NO

R294X

GDD, microcephaly, poor speech, unsteady gait, ataxia
History of seizures, microcephaly, non-verbal, spastic diparesis, scoliosis, facial dysmorphisms

Regression, seizures, microcephaly, autistic features, hand-wringing, scoliosis

Seizures, spastic diplegia, non-verbal, hyperventilation, hand-flapping, hypotonia, facial dysmorphisms
Not available

Seizures, stereotypic hand behaviors, bruxism, occasional abnormal breathing patterns

Not available

Speech delay, MR, behavioral problems, hand-wringing, hyperventilation, inappropriate laughter, drooling

Not available

GDD, intractable epilepsy, ataxia, obesity, hypertriglyceridemia

Stereotypic hand movements, fine motor deficits, non-verbal, abnormal EEG

GDD, seizures, abnormal MRI, left hemiparesis, hand-wringing, non-verbal, history of bruxism

Dificulty walking, delayed speech, white matter changes on MRI

GDD, microcephaly, hypotonia

AS

Not available

Not available

Not available

Hyperventilation, manneristic hand movements, scoliosis, microcephaly

GDD, microcephaly, seizures, hand-wringing, bruxism, dysmorphic features, non -verbal

GDD, microcephaly, seizures, syndactyly

GDD, regression, microcephaly, seizures, hand-wringing, cerebral atrophy, bruxism

Not available

GDD, hypotonia, dysmorphic features, plagiocephanly, scoliosis, osteoporosis, abnormal EEG

GDD, no eye contact, recurrent blinking, repetitive behaviours

GDD, microcephaly, strabismus
Not available

GDD: Global Developmental Delay; Dev.: Developmental; pbs: problems; PWS: Prader-Willi Syndrome; SD: Seizures Disorder; AS: Angelman Syndrome; PDD: pervasive developmental disorders; MR: mental retardation; SMS: Smith-Magenis Syndrome; EEG: electroencephalogram; MRI: magnetic resonance imaging.

Lasergene Primer select program. The PCR products were loaded on $2 \%$ agarose gel to confirm amplification before analysis for base changes by denaturing high performance liquid chromatography (DHPLC) (WAVE Nucleic Acid Fragment Analysis System from Transgenomic, San Jose, CA). Solvent A consisted of $0.1 \mathrm{~mol} / \mathrm{L}$ triethylammonim acetate (TEAA) and $25 \%$ acetonitrile and solvent $\mathrm{B}$ contained $1 \mathrm{M}$ triethylammonim acetate, $25 \%$ acenonitril. PCR products showing a chromatographic variation on dHPLC were sequenced directly on an automatic sequencer (Gene Reader 4200). The sequencing data was analyzed using DNA Star software SeqMan (Lasergene). Exon 1 was PCR amplified and sequenced in all patients as recently described. ${ }^{14}$

\section{RESUlTS}

The MECP2 gene was retrospectively analyzed for mutations in banked DNA from a total of 136 patients with a presumptive diagnosis of RTT. Average age of the affected subjects was 13 years, with a range of five to 46 years. We identified a total of 33 different MECP2 mutations, presented in Table 1. Group 1 was a historic cohort of 35 patients suspected of having RTT. Organized diagnostic criteria were not utilized in these patients. Their clinical features are summarized in Table 3. Results from mutational analysis in this group revealed mutations in seven individuals $(20 \%)$ (Table 1). Five of the nine common point mutations, T170M, R180X, R267X, R306X, and R318C were found in this group. All mutations in Group 1 have been seen previously in classical RTT patients. 
In Group 2, which included subjects diagnosed with a strict adherence to the RTT criteria, mutations were detected in 73 out of 101 individuals (72\%). All previous common RTT point mutations, namely R118W, R145C, T170M, R180X, R267X, $\mathrm{R} 282 \mathrm{X}, \mathrm{R} 306 \mathrm{X}$, and R318C were detected in this group, except one, A152V (A140V). These eight recurrent mutations account for $68.5 \%$ of our Group 2 mutations, with T170M being the most frequent (16 times). Three patients had previously undescribed mutations, two in exon 3 (762 (del C), and P284S) and one in exon 1 (Table 1). The exon 1 mutation, a 1A-T substitution (ATG->TTG), changes the first Methionine codon into a Leucine. The prediction is that MECP2E1 translation would be greatly or totally hindered due to absence of a start codon. MECP2E2 would be normally made (and appears unable to rescue the disease phenotype).

None of the mutations in Group 1 or 2 were observed in any of the parents of our patients, confirming that the great majority of mutations in RTT are de novo. Polymorphisms were found in both groups during our mutation analysis. They are: S206S, G264G, T311T, S422S and K357K. G264G and S422S have not previously been reported. Finally, a hitherto unreported variation, P431S, located at the C-terminus of the MECP2 gene, was found to be transmitted from a normal mother to an RTTaffected girl. We label this sequence alteration "unclassified variant", as recently proposed. ${ }^{9}$

\section{Discussion}

In this study we have analyzed the entire coding sequence of the MECP2 gene in two cohorts of subjects, grouped according to the use of diagnostic procedure to make a diagnosis. We wanted to evaluate the impact of the use of stringent clinical criteria on MECP2 mutation detection rate. Our MECP2 screen revealed the presence of multiple mutations in both groups of patients; however, the detection rate in Group 1 was much lower (20\%) than in Group 2 (72\%). These observations indicate that diagnostic procedures strongly influence mutation detection rates. While the clinical overlap seen in Group 1 compared to Group 2 is substantial, subjects in the former group may have a more genetically heterogeneous etiology than those with a more stringent RTT diagnosis. From the clinical point of view, this observation is important, because the majority of subjects diagnosed without the use of RTT criteria may represent other diseases. In fact, many in Group 1 were given a differential diagnosis of Angelman syndrome (Table 3). Rett syndrome and Angelman syndrome are both neurodevelopmental disorders characterized by severe intellectual disability, microcephaly, speech problems, movement disorders with gait and/or truncal ataxia, and occasionally a similar facial appearance. As mentioned by Ellaway and colleagues ${ }^{20}$, RTT is probably the most common mimicker during the infant and toddler ages and Angelman Syndrome might represent a phenocopy for RTT. ${ }^{20}$ The clear distinction between the two syndromes will continue evolving over time. On the other hand, in the present study, in those who were found negative for MECP2 coding sequence mutations, it is still possible they have other mutations such as regulatory mutations or large insertions or deletions that would not be detected by the methods utilized in this study. However, it is unlikely that such a mutation subgroup would be differentially represented Group 1. Additional genetic alterations have been associated with the RTT phenotype, even in patients with a typical MeCP2 mutation. Longo et $\mathrm{al}^{21}$ recently reported three patients with Rett syndrome and rearrangements of chromosome 15q11-13, a region known to be implicated in autistic phenotypes. $^{21}$ This suggests the possibility of the role of additional genes with the RTT phenotype, although further studies are necessary to confirm this association. Indeed, in a recent review of Weaving et al. ${ }^{22}$, at least seven published atypical RTT cases have been found to have mutation in the Xlinked CDKL5/STK9 gene. This serine/threonine-protein kinase of unknown function may represent a potential candidate gene for RTT cases without any MECP2 mutation.

While most of the observed mutations in this study have been reported previously, three are new, including one in the newly characterized coding first exon. One mutation, P284S, would seriously alter the $\mathrm{MeCP} 2$ protein secondary structure by removing the proline bend at position 284. Another, 762 (del C), shifts the reading frame and results in premature truncation. The exon 1 mutation (1A->T) removes the exon 1 initiation codon, which would prevent any MeCP2E1 protein from being made. In the MECP2E2 transcript it will represent nothing more than a single nucleotide change in the 5'UTR. Might this have an effect on MECP2E2 protein production? Kriaucionis and Bird ${ }^{15}$ recently showed, in tissue culture experiments, that the four-exon MECP2E2 transcript makes a short peptide initiated at the start codon (ATG) in exon 1 and terminated in the stop codons preceding the MECP2E2 start site in exon 2. They demonstrated that if the exon 1 start is removed and the short peptide abolished, the translation of MECP2E2 increases dramatically. Here, we have a patient replicating the Kriaucionis and Bird experiment. If subsequent experiments indeed show that in this patient MECP2E2 translation is enhanced by the exon 1 ATG A$>\mathrm{T}$ mutation, then this would provide crucial new insight into RTT. It would imply that MECP2E2 cannot compensate for absence of MECP2E1, and that MECP2E1 is necessary and sufficient for RTT. These experiments are underway.

As mentioned by Hagberg and colleagues ${ }^{19}$ even though we now know the major genetic cause of RTT, this disease remains so far a clinical diagnosis. From a scientific and socio-economic point of view, the use of efficient and well defined clinical criteria is very important for many reasons: (1) In order to replicate research findings, such as mutation gene screening, it is essential to use the same phenotypic selection method. (2) In heterogeneous genetic disorders, where more than one gene locus might be involved, it is important to be able to discriminate those who harbour a mutation in order to only focus on those who do not have mutations to better homogenize the search of the unknown locus. (3) The more the diagnostic procedure is precise; the more appropriate treatments can be applied to the affected child. (4) The diagnosis of RTT remains clinical and this is a critical step that leads (or not) to MECP2 mutation gene screening, especially since the cost of MECP2 testing is high (currently varies from $\$ 500$ to $\$ 950$ US).

Our results show that implementation of better clinical diagnostic procedures improves the rate of MECP2 mutation detection. Mutations in the MECP2 exon 1 occur in $2 / 136$ or $1.5 \%$ of RTT patients, and therefore this exon should be included in diagnostic mutation searches in this devastating disease. 


\section{REFERENCES}

1. Hagberg B. Clinical manifestations and stages of Rett syndrome. Ment Retard Dev Disabil Res Rev 2002;8:61-65.

2. Schanen C, Houwink EJ, Dorrani N, et al. Phenotypic manifestations of MECP2 mutations in classical and atypical Rett syndrome. Am J Med Genet 2004;126A:129-140.

3. Weaving LS, Williamson SL, Bennetts B, et al. Effects of MECP2 mutation type, location and X-inactivation in modulating Rett syndrome phenotype. Am J Med Genet 2003;118A:103-114.

4. Naidu S, Bibat G, Kratz L, et al. Clinical variability in Rett syndrome. J Child Neurol 2003;18:662-668.

5. Dotti MT, Orrico A, De Stefano N, et al. A Rett syndrome MECP2 mutation that causes mental retardation in men. Neurology 2002;58:226-230.

6. Orrico A, Lam C, Galli L, et al. MECP2 mutation in male patients with non-specific X-linked mental retardation. FEBS Lett 2000;481:285-288

7. Meloni I, Bruttini M, Longo I, et al. A mutation in the Rett syndrome gene, MECP2, causes X-linked mental retardation and progressive spasticity in males. Am J Hum Genet 2000;67:982985.

8. Amir RE, Van den Veyver IB, Wan M, et al. Rett syndrome is caused by mutations in X-linked MECP2, encoding methyl-CpGbinding protein 2. Nat Genet 1999;23:185-188.

9. Miltenberger-Miltenyi G, Laccone F. Mutations and polymorphisms in the human methyl CpG-binding protein MECP2. Hum Mutat 2003;22:107-115.

10. Laccone F, Junemann I, Whatley S, et al. Large deletions of the MECP2 gene detected by gene dosage analysis in patients with Rett syndrome. Hum Mutat 2004;23:234-244.

11. Ariani F, Mari F, Pescucci C, et al. Real-time quantitative PCR as a routine method for screening large rearrangements in Rett syndrome: Report of one case of MECP2 deletion and one case of MECP2 duplication. Hum Mutat 2004;24:172-177.

12. Karteszi J, Hollody K, Bene J, et al. [Mutational analysis of the MECP2 gene by direct sequencing in Hungarian patients with Rett syndrome]. Orv Hetil 2004;145:909-911.
13. Schollen E, Smeets E, Deflem E, et al. Gross rearrangements in the MECP2 gene in three patients with Rett syndrome: implications for routine diagnosis of Rett syndrome. Hum Mutat 2003;22:116120.

14. Mnatzakanian GN, Lohi H, Munteanu I, et al. A previously unidentified MECP2 open reading frame defines a new protein isoform relevant to Rett syndrome. Nat Genet 2004;36:339-341.

15. Kriaucionis S, Bird A. The major form of MeCP2 has a novel Nterminus generated by alternative splicing. Nucleic Acids Res 2004;32:1818-1823.

16. Rett A. Über ein eigenartiges hirnatrophisches Syndrom bei Hyperammonämie im Kindesalter. Wien Lin Wochenschr 1966:723726.

17. Hagberg B, Aicardi J, Dias K, Ramos O. A progressive syndrome of autism, dementia, ataxia, and loss of purposeful hand use in girls: Rett's syndrome: report of 35 cases. Ann Neurol 1983;14:471479.

18. Hagberg B. Rett's syndrome: prevalence and impact on progressive severe mental retardation in girls. Acta Paediatr Scand 1985; 74:405-408.

19. Hagberg B, Hanefeld F, Percy A, Skjeldal O. An update on clinically applicable diagnostic criteria in Rett syndrome. Comments to Rett Syndrome Clinical Criteria Consensus Panel Satellite to European Paediatric Neurology Society Meeting, Baden Baden, Germany, 11 September 2001. Eur J Paediatr Neurol 2002; 6:293-297.

20. Ellaway C, Buchholz T, Smith A, et al. Rett syndrome: significant clinical overlap with Angelman syndrome but not with methylation status. J Child Neurol 1998;13:448-451.

21. Longo I, Russo L, Meloni I, et al. Three Rett patients with both MECP2 mutation and 15q11-13 rearrangements. Eur J Hum Genet 2004;12:682-685.

22. Weaving LS, Ellaway CJ, Gecz J, Christodoulou J. Rett syndrome: clinical review and genetic update. J Med Genet 2005;42:1-7. 